\title{
Comparison of Simulation-Based versus Cadaveric- Tissue-Based Ocular Trauma Training on Novice Ophthalmologists: Repair of Corneal Laceration Model
}

\author{
Boonkit Purt, MD ${ }^{1,2}$ Timothy Ducey, MD ${ }^{1}$ Sean Sykes, $\mathrm{DO}^{1}$ Joseph F. Pasternak, MD ${ }^{1,2}$ \\ Denise S. Ryan, MS ${ }^{3}$ Rose K. Sia, MD ${ }^{3}$ Marcus H. Colyer, MD ${ }^{1,2}$
}

\footnotetext{
${ }^{1}$ Ophthalmology Service, Walter Reed National Military Medical Center, Bethesda, Maryland

2 Department of Surgery, Uniformed Services University of the Health Sciences, Bethesda, Maryland

${ }^{3}$ Warfighter Refractive Eye Surgery Program and Research Center, Fort Belvoir Community Hospital, Fort Belvoir, Virginia
}

\author{
Address for correspondence Boonkit Purt, MD, Walter Reed National \\ Military Medical Center, Bethesda, MD \\ (e-mail: boonkitp@gmail.com).
}

\begin{abstract}
Keywords

- ophthalmology

- simulation

- training

- cornea

- trauma

Purpose The aim of this study was to evaluate whether the simulated tissue models may be used in place of animal-based model for corneal laceration repair for surgical skills acquisition.

Design Prospective randomized controlled trial.

Participants Seventy-nine military and civilian 2nd- and 3rd-year ophthalmology residents and 16 staff ophthalmologists participating in the Tri-Service Ocular Trauma Skills Laboratory at the Uniformed Services University (Bethesda, MD).

Methods Resident ophthalmologists underwent preliminary evaluation of their ability to close a 5-mm linear, full-thickness corneal laceration involving the visual axis. They then were randomized to undergo 90 to 120 minutes of either simulatorbased (SIM) or swine cadaveric-tissue-based (CADAVER) corneal laceration repair. The same evaluation was performed post training. On a more limited basis, the study was repeated for attending ophthalmologists to act as a pilot for future analysis and test efficacy for "refresher" training.

Main Outcome Measures Successful wound closure with secondary outcomes of suture length, tension, depth, and orientation, as graded by attending ophthalmologists.

Results No significant difference in CADAVER versus SIM groups in the primary outcome of watertight wound closure of the corneal laceration. CADAVER group performed better than SIM group for certain metrics (suture depth, $p=0.009$; length, $p=0.003$; and tension, $p=0.043$ ) that are associated with poor wound closure and increased amount of induced corneal astigmatism. For attending ophthalmologists, six of the eight in each group (SIM and CADAVER) retained or improved their skills.

received

October 4, 2020 accepted after revision January 12, 2021

DOI https://doi.org/ $10.1055 / \mathrm{s}-0041-1725093$. ISSN 2475-4757.

(C) 2021. The Author(s).

This is an open access article published by Thieme under the terms of the Creative Commons Attribution-NonDerivative-NonCommercial-License, permitting copying and reproduction so long as the original work is given appropriate credit. Contents may not be used for commercial purposes, or adapted, remixed, transformed or built upon. (https://creativecommons.org/ licenses/by-nc-nd/4.0/)

Thieme Medical Publishers, Inc., 333 Seventh Avenue, 18th Floor, New York, NY 10001, USA
\end{abstract}


Conclusions For resident ophthalmologists, SIM training is sufficient for achieving the primary outcome of watertight wound closure. However, CADAVER training is superior for wound metrics for the ideal closure. For attending ophthalmologists, SIM training may be useful for retention of skills.

For military ophthalmologists, the management of ocular trauma is an important part of their repertoire, especially in a deployed setting. However, ocular trauma remains an area of limited exposure for many residents and attending ophthalmologists. Many across the country are not routinely called upon for primary treatment of ocular or orbital trauma. This is further compounded by the lack of effective and/or established surgical simulators to permit easily accessible maintenance of skills. Overall, this presents significant problems when military ophthalmologists transition to the deployed environment and the Role 3 (Combat Support Hospital), when they may be called upon to care for large numbers of ocular and orbital trauma patients in concert with other bodily injuries. In the U.S. Department of Defense (DoD), the roles of personnel in trauma and the health care system starts from Role 1 with emergency first responder and tactical care and ends with Role 4 , which is a fully capable hospital. A Role 3 is similar to a Role 4 in that it includes the spectrum of medical, surgical, dental, and psychological care, but is intended for short-term care.

This is particularly important for military ophthalmologists, given the high acuity level of many ocular injuries sustained in combat. A recent review of Joint Theater Trauma Registry information in Kandahar, Afghanistan, revealed 559 open globe injuries between June 2009 and June 2012. Another analysis by Vlasov et al found that $77.7 \%$ (206 of 265) of eye injuries in soldiers evacuated from Iraq and Afghanistan to Walter Reed Army Medical Center from 2001 to 2011 were open globe injuries. ${ }^{2}$ Among the military population, ocular injuries accounted for the fourth most common injury during Operation Iraqi Freedom and Operation Enduring Freedom. ${ }^{3}$ At most military and civilian training facilities, residents struggle to meet trauma minimums of four open globe injuries. Any opportunity to increase the volume and quality of trauma training for both resident and staff ophthalmologists is critical in preparing for what an ophthalmologist in a Role 3 hospital will face.

Surgical simulation has become standard training in many fields of surgery for resident and attending physicians alike, including in ophthalmology where the Eyesi (VRmagic, Mannheim, Germany) has gained widespread acceptance for teaching cataract and vitreoretinal surgery. Multiple recent studies have proven the efficacy of training with this simulator in preparing residents for cataract surgery. ${ }^{4,5}$ However, simulation of nonintraocular ophthalmic surgery is lacking. Current resident training largely revolves around use of animal tissue, most often from exenterated orbital contents of deceased animals, most frequently swine due to the anatomical similarities to human eyes. However, there are significant limitations to these techniques including availability, separation of space and instruments for animal use, storage, and waste management issues. In some instances, live specimens under general anesthesia are used to better simulate clinically realistic intraoperative scenarios such as bleeding and intraocular pressure changes. Research facilities must have an Institutional Animal care and Use Committee (IACUC) to oversee use of animals in experiments and to ensure compliance with the Animal Welfare Act. This places further restrictions on availability of live-tissue training. Validation of a simulated tissue model could alleviate some of the difficulties associated with these training options. The DoD has mandated the reduction in use of animals for medical training when "if such methods produce scientifically or educationally valid or equivalent results." Similarly, in the civilian sector, 99\% of Advanced Trauma Life Support training programs in the United States and Canada do not use animals. ${ }^{7}$ The Bioniko ophthalmic surgery models (Bioniko LLC, Miami, $\mathrm{FL}$ ) are a group of models designed for use in surgical training of various ophthalmic surgical techniques. The Bioniko model studied previously as a training platform for penetrating keratoplasty ${ }^{8}$ was limited in that it evaluated the surgeon's ability to complete the task on the model without a comparison to live tissue. ${ }^{8}$ Our study aims to validate these models as substitutes for live or deceased animal tissue by assessing a surgeon's ability to perform a time-limited corneal laceration repair after training conducted on deceased or simulated tissue.

\section{Methods}

The study was reviewed by the Uniformed Services University of the Health Sciences Institutional Review Board prior to initiation and was determined to be under exempt research category. The United States Army Medical Research and Material Command Human Research Protection Office concurred with the determination and Animal Care and Use Review Office approval was obtained. The study was also approved by the IACUC.

As part of the same ophthalmic training simulator study described by Sykes et al, ${ }^{9}$ over a 4-year period, 79 military and civilian 2nd- and 3rd-year ophthalmology residents and 16 staff ophthalmologists participating in the Tri-Service Ocular Trauma Course, an annual hands-on training course for residents to diagnose, train, and treat ocular trauma, took part in the study. Residents came from a mix of military (four programs: Walter Reed National Military Medical Center, Madigan Army Medical Center, San Antonio Military Medical Center, Naval Medical Center San Diego) and civilian programs (six programs: Georgetown University, George Washington University, Howard University, Eastern Virginia Medical School, Pennsylvania State University, Sinai Hospital). 


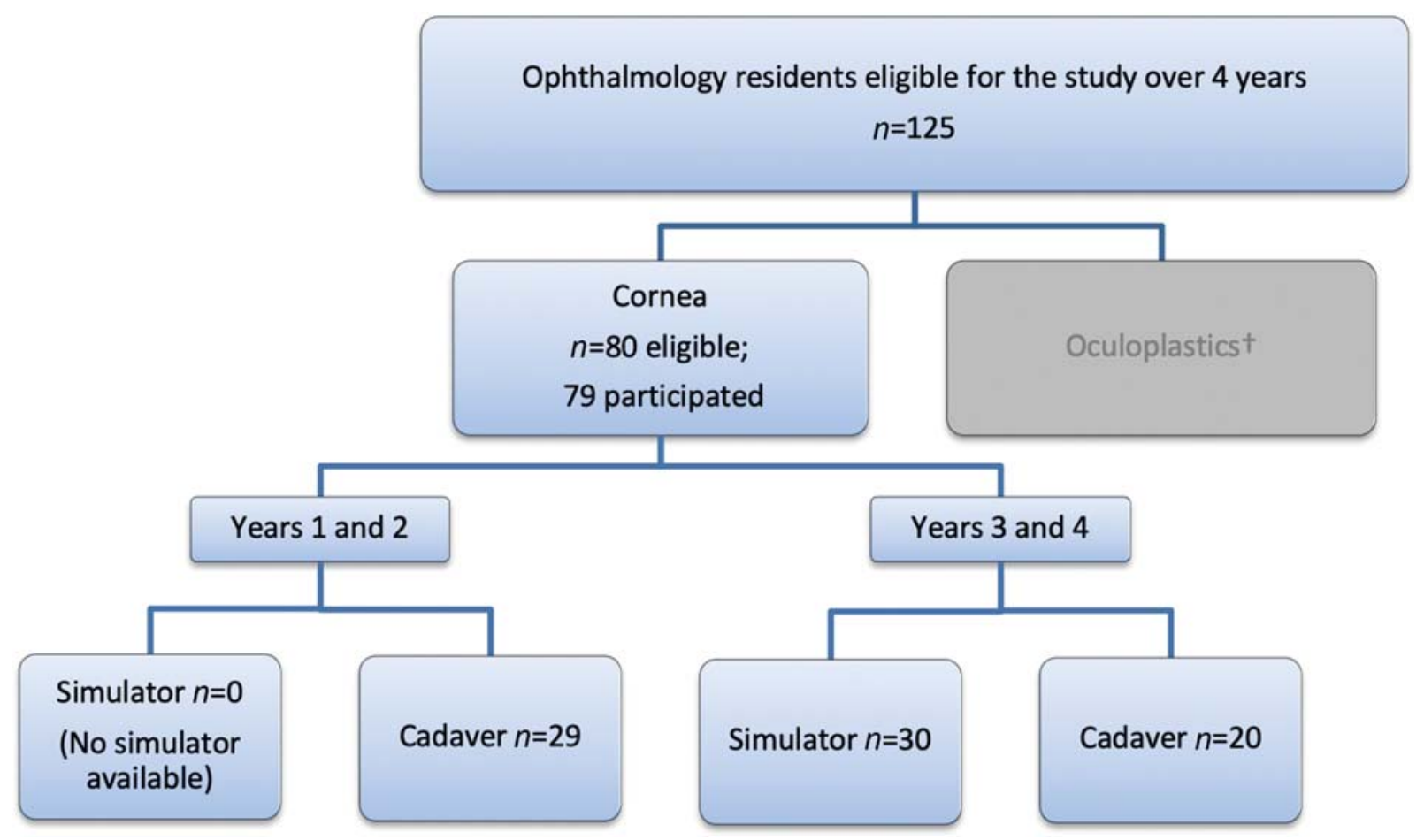

Fig. 1 Resident study structure, years $1-4 .{ }^{*}$ Randomization based on time required to close baseline wound. $\dagger$ Sykes et al. ${ }^{9}$

Residents underwent training and testing of their ability to close a 5-mm linear, full-thickness corneal laceration involving the visual axis. Prior to training, a preliminary evaluation of surgical skill via testing on cadaveric tissue was performed. The variable of "time required to repair a laceration" (or "time to completion") was recorded as a continuous variable measured in seconds and was used to sequence participants as a measure of surgeon efficiency in surgical repair. This preliminary evaluation was designated as before-training repair (BTR). As in Sykes et al, ${ }^{9}$ after BTR "time to completion" was recorded, resident participants were stratified according to the median "time to completion," which was deemed the group's baseline. This measure then served as a surrogate for the group's baseline surgical skill level. Resident participants were then allocated using stratified randomization to undergo either 90 to 120 minutes of simulator-based (SIM) training on a three-dimensional (3D)-printed synthetic ophthalmic tissue or traditional swine cadaveric-tissue-based (CADAVER) training, both with a faculty preceptor (-Fig. 1).

Of note, a virtual reality-based Ocular Trauma Microsurgery Simulator was originally proposed for use rather than the eventual Bioniko model. However, despite considerable progress, it was deemed insufficient for use. Thus, for the first 2 years of the study, testing was only completed for the CADAVER group. An alternate cornea simulator, the Bioniko Cordelia Recovery Simulator, was ultimately selected for use in the later 2 years of the study. Thus, randomization to both groups did not occur until 2016 and beyond.

For each training session, a linear central laceration was created in the model and subsequently repaired with 10-0 nylon suture as guided by a faculty preceptor. Participants randomized to the SIM group used the Bioniko Cordelia Recovery Simulator model (-Fig. 2), a model made from a
3D-printed polyacrylate material consisting of a single-use corneoscleral ring held in place by a multiuse apparatus. Participants in the CADAVER group used an exenterated porcine eye model for training.

Instruction and grading of successful repair of a corneal laceration included the following variables: number of sutures required to close the laceration, time to repair the wound, tissue apposition, suture depth, suture tension, suture length, whether the knots were buried, and successful repair of the laceration. Prior to grading, faculty graders were given a series of test eyes to calibrate their grading concurrence with standard descriptions correlating to level of repair. The median score of the three observations was used for analysis. In assessing the successful completion of the exercise, the third grader was used as a tiebreaker in the event of a disagreement between the two graders. A schematic of the ideal suture repair is shown in - Figure 3.

The following guidelines were used for grading: participants either achieved or did not achieve surgically appropriate approximation of the laceration as evaluated by the staff faculty grader. The number of sutures needed to close the laceration was recorded as a discrete value. While there is no correct number of sutures for this exercise, too few sutures may lead to poor closure and too many sutures may increase surgical time and may lead to increased surface irregularity and irregular astigmatism. Tissue apposition, suture depth, suture tension, and suture length were graded on an ordinal scale with four grades: $1=$ Poor, $2=$ Fair, $3=$ Good, and $4=$ Excellent, as graded by the course instructors. The scoring criteria is described in - Table 1 . These factors were selected to measure the overall quality of the repair while minimizing induced morbidity (e.g., from astigmatism). Over- or under-correction of suture depth leads to 


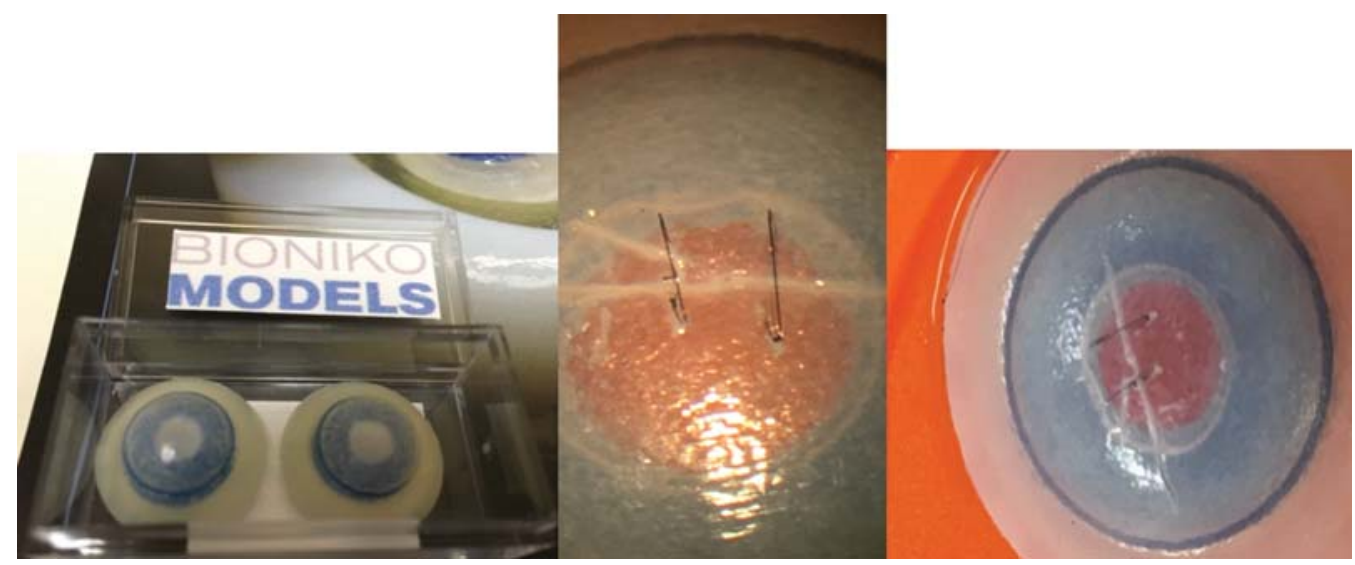

Fig. 2 Bioniko Kerato ophthalmic surgery model with examples of Bioniko corneal laceration repair.

\section{A 5-mm Central Corneal Laceration Placement}

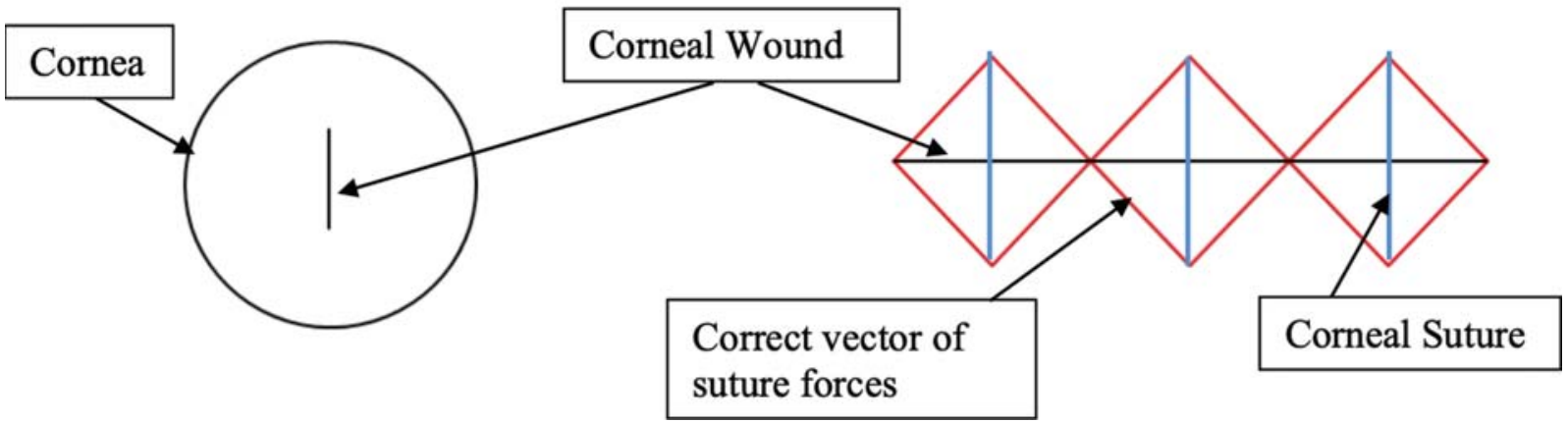

Fig. 3 Diagram of intended corneal wound and ideal repair. As noted in the diagram, black represents the laceration, blue represents suture, and red represents vector forces. (A) 5-mm central corneal laceration; (B) ideal corneal suture placement.

Table 1 Scoring of laceration repair

\begin{tabular}{|l|l|l|l|l|}
\hline Score & $\mathbf{1}$ & $\mathbf{2}$ & $\mathbf{3}$ & $\mathbf{4}$ \\
\hline $\begin{array}{l}\text { Tissue } \\
\text { apposition }\end{array}$ & $\begin{array}{l}\text { Wound edge override } \\
>0.5 \mathrm{~mm} \text { - Seidel positive } \\
\text { with anterior chamber } \\
\text { collapse }\end{array}$ & $\begin{array}{l}\text { Wound edge override of } \\
0.25-0.5 \mathrm{~mm} \text { - Seidel } \\
\text { positive without cham- } \\
\text { ber collapse }\end{array}$ & $\begin{array}{l}<0.25 \mathrm{~mm} \text { wound edge } \\
\text { override; no gap in tissue } \\
\text { interface but some evi- } \\
\text { dence of aqueous } \\
\text { leakage }\end{array}$ & $\begin{array}{l}\text { No wound edge override; } \\
\text { no leakage of aqueous } \\
\text { from closure }\end{array}$ \\
\hline $\begin{array}{l}\text { Suture } \\
\text { depth }\end{array}$ & $\begin{array}{l}\text { Uneven suture depth } \\
\text { with no consistency }\end{array}$ & $\begin{array}{l}<50 \% \text { consistency in su- } \\
\text { ture depth }\end{array}$ & $\begin{array}{l}>50 \% \text { consistency in su- } \\
\text { ture depth }\end{array}$ & $\begin{array}{l}100 \% \text { consistency in su- } \\
\text { ture depth }\end{array}$ \\
\hline $\begin{array}{l}\text { Suture } \\
\text { tension }\end{array}$ & $\begin{array}{l}\text { Over- or under-tightness } \\
\text { resulting in excessive } \\
\text { corneal "compression" } \\
\text { with Descemet striae or } \\
\text { leaky wound }\end{array}$ & $\begin{array}{l}\text { Moderately excessive } \\
\text { tension with modest cor- } \\
\text { neal striae and visible } \\
\text { corneal stromal irregu- } \\
\text { larity at the microscope }\end{array}$ & $\begin{array}{l}\text { Smooth, consistent su- } \\
\text { ture asses with only } \\
\text { modest bunching of } \\
\text { tissue }\end{array}$ & $\begin{array}{l}100 \% \text { consistency in su- } \\
\text { ture tension with } \\
\text { minimal/no corneal } \\
\text { steepening or laxity of } \\
\text { sutures }\end{array}$ \\
\hline $\begin{array}{l}\text { Suture } \\
\text { length }\end{array}$ & $\begin{array}{l}\text { Overly short sutures or } \\
>50 \% \text { asymmetry (of the } \\
\text { suture length) across the } \\
\text { wound }\end{array}$ & $\begin{array}{l}\text { Moderately short sutures } \\
\text { or } 25-50 \% \text { asymmetry } \\
\text { across the wound }\end{array}$ & $\begin{array}{l}\text { Appropriate length } \\
\text { sutures and }<25 \% \text { asym- } \\
\text { metry across the wound }\end{array}$ & $\begin{array}{l}100 \% \text { appropriate length } \\
\text { and } 100 \% \text { symmetry (or } \\
0 \% \text { asymmetry) across } \\
\text { the wound }\end{array}$ \\
\hline
\end{tabular}

reduced consistency and poor apposition of tissue due to variability in compression laterally and antero-posteriorly. Suture tension and overly long/short sutures contribute to the amount of induced astigmatism and may lead to inadequate closure or excessive compression.

\section{B Ideal Corneal Suture}

Corneal Suture
Successful repair was scored as a categorical value, yes or no. Upon completion of deliberate training, a participant's ability to close a 5-mm linear, full-thickness corneal laceration involving the visual axis was reassessed and designated post-training repair (PTR). 
In addition to graded metrics, participants in the course were given a survey to assess level of training, prior simulator experience, and prior surgical experience. After PTR, some participants provided additional feedback to assess their experience with the simulator and its usefulness in training and maintenance of skills. The following research questions were evaluated:

1. How does simulator training compare with gold standard live-tissue training in a time-limited ocular trauma training course?

2. Are ocular trauma simulation platforms feasible in an ocular trauma training course?

3. Are the testing measures being analyzed sufficiently measurable to differentiate skills acquisition (validity testing/refinement)?

To assess the relative value of simulator training on participants with a different level of expertise, ophthalmology staff (eight cornea fellowship-trained and eight comprehensive general ophthalmologists or other subspecialty) were selected to participate and were evenly divided between CADAVER and SIM groups. All completed BTR followed by self-training for up to 120 minutes and reassessment as described for the resident group. Acknowledging the small sample size, the intent of this subset was to provide proof-of-content evaluation regarding the role of simulators in maintenance or refreshment of skills for already trained, but "rusty" ophthalmologists.

Continuous data were reported as median and interquartile ranges and nonparametric tests were performed to compare preoperative to postoperative change by treatment group (Wilcoxon signed-rank test) or between groups (Mann-Whitney test). Categorical data were presented as number and percentage and the Fischer's exact test was used for comparison of the treatment groups. A $p$-value of $<0.05$ was considered statistically significant. All data analyses were performed using SPSS version 21.0 (IBM, Inc.).

\section{Results}

Participant demographics and prior simulator and corneal laceration repair experience are presented in -Table 2. Between the SIM and CADAVER groups, gender and age were similar. While the CADAVER training group included a higher percentage of residents further along in training (SIM, 3.3\% versus CADAVER, $16.3 \%$ ), this did not correspond with more experience in the number of prior corneal laceration repairs. Prior simulator experience was also similar between groups. Prior simulator experience refers to any simulator use, though by far and large, most had been exposed to both cadaveric and virtual simulation, though this question was not directed specifically to corneal laceration repair simulation and rather directed toward use of any of these models for ophthalmic training. Of the SIM group, 29/30 residents had experience with a simulator (live or virtual), and of those, 28/29 had experience with both. Similarly, of the LIVE group, 47/49 had experience with a simulator (live or virtual) and of those, 45/47 had experience
Table 2 Resident group demographics and survey of prior simulation and corneal laceration repair experience

\begin{tabular}{|c|c|c|}
\hline & $\begin{array}{l}\text { SIM training } \\
(n=30)\end{array}$ & $\begin{array}{l}\text { CADAVER training } \\
(n=49)\end{array}$ \\
\hline \multicolumn{3}{|l|}{ Demographics } \\
\hline Males & 24 & 37 \\
\hline Females & 6 & 12 \\
\hline \multicolumn{3}{|l|}{ Age $(y)$} \\
\hline $26-35$ & 28 & 44 \\
\hline $36-45$ & 2 & 5 \\
\hline \multicolumn{3}{|l|}{ Status } \\
\hline 2nd year resident & $29(96.7 \%)$ & $41(83.7 \%)$ \\
\hline 3rd year resident & $1(3.3 \%)$ & $8(16.3 \%)$ \\
\hline \multicolumn{3}{|l|}{ Prior SIM use (h) } \\
\hline $0-3$ & 3 & 2 \\
\hline $4-10$ & 5 & 10 \\
\hline $11-20$ & 9 & 14 \\
\hline$>20$ & 12 & 21 \\
\hline \multicolumn{3}{|c|}{ Prior number of corneal lacerations } \\
\hline 0 & 16 & 33 \\
\hline $1-4$ & 13 & 33 \\
\hline $5-10$ & 1 & 3 \\
\hline$>10$ & 0 & 0 \\
\hline \multicolumn{3}{|c|}{ Prior number of cataract surgeries } \\
\hline $0-20$ & 15 & 15 \\
\hline $21-50$ & 12 & 16 \\
\hline $51-100$ & 2 & 13 \\
\hline$>100$ & 1 & 5 \\
\hline
\end{tabular}

Note: SIM refers to simulator-based training while CADAVER refers to cadaveric-tissue-based training.

with both. Of note, none of the residents had experience with the Bioniko model, which was used in the SIM group.

Pre- and post-training metrics within each group (SIM and CADAVER) were compared and are presented in -Table 3. There was a significant difference in suture depth among the SIM group (BTR, 2.0; PTR, 3.0; $p=0.045$ ). Otherwise, the SIM group metrics were not significantly different from pre- to post-training evaluation. There were significant differences pre- to post training in the CADAVER group metrics except tissue apposition. There was no difference in successful completion of the exercise within each group. The comparisons between the SIM and CADAVER groups, pre- and post training, are presented in -Table $\mathbf{4}$. There were no significant differences noted pretraining. Post training, there was a significant difference in suture depth, suture tension, and suture length. While the median suture depth is the same, the CADAVER group performed better.

While CADAVER training resulted in greater improvement between BTR and PTR ( - Table $\mathbf{3}$ ) and better scores after training between groups ( - Table 4 ), neither group showed a 
Table 3 Before-training versus post-training scoring metrics in the SIM and CADAVER groups (Resident cohort)

\begin{tabular}{|c|c|c|c|c|c|c|}
\hline Measures & SIM & & & CADAVER & & \\
\hline Median (IQR) & Before training & Post training & $p$-Value & Before training & Post training & $p$-Value \\
\hline Number of sutures & $5(5-7)$ & $6(5-7)$ & 0.210 & $6(5-8)$ & $6(5-7)$ & 0.229 \\
\hline Time (sec) & $\begin{array}{l}2,492 \\
(2,029-3,114)\end{array}$ & $\begin{array}{l}2,255 \\
(1,883-2,952)\end{array}$ & 0.063 & $\begin{array}{l}2,515 \\
(1,919-3,521)\end{array}$ & $\begin{array}{l}2,019 \\
(1,574-2,862)\end{array}$ & $<0.001^{c}$ \\
\hline Tissue apposition ${ }^{\mathrm{a}}$ & $3.0(2.0-3.0)$ & $3.0(2.0-3.0)$ & 0.231 & $3.0(2.0-3.0)$ & $3.0(2.5-3.0)$ & 0.101 \\
\hline Suture depth ${ }^{a}$ & $2.0(1.8-3.0)$ & $3.0(2.0-3.0)$ & $0.045^{c}$ & $2.0(2.0-3.0)$ & $3.0(3.0-4.0)$ & $<0.001^{c}$ \\
\hline Suture tension ${ }^{\mathrm{a}}$ & $2.0(1.0-3.0)$ & $2.0(2.0-3.0)$ & 0.076 & $2.0(2.0-3.0)$ & $3.0(2.0-3.0)$ & $<0.002^{c}$ \\
\hline Suture length ${ }^{a}$ & $2.0(1.0-3.0)$ & $2.0(2.0-3.0)$ & 0.140 & $1.0(1.0-2.0)$ & $3.0(2.0-3.0)$ & $<0.001^{\mathrm{c}}$ \\
\hline Knots buried ${ }^{\mathrm{b}}$ & $3.0(1.0-3.0)$ & $2.0(1.0-3.0)$ & 0.057 & $3.0(1.0-3.0)$ & $1.0(1.0-2.0)$ & $<0.001^{c}$ \\
\hline
\end{tabular}

Note: SIM refers to simulator-based training while CADAVER refers to cadaveric-tissue-based training. IQR, interquartile range.

${ }^{\mathrm{a} S}$ Scale: 1 (poor) to 4 (excellent).

bscale: 1 (100\% buried) to 3 ( $<50 \%$ buried).

${ }^{c} p<0.05$.

Table 4 SIM versus CADAVER groups scoring metrics before training and post training (Resident cohort)

\begin{tabular}{|c|c|c|c|}
\hline Before training & $\operatorname{SIM}(n=30)$ & CADAVER $(n=49)$ & $p$-Value \\
\hline Number of sutures & $6(5-7)$ & $6(5-8)$ & 0.315 \\
\hline Time (sec) & $2,592(2,029-3,114)$ & $2,515(1,920-3,521)$ & 0.750 \\
\hline Tissue apposition ${ }^{\mathrm{a}}$ & $3.0(2.0-3.0)$ & $3.0(2.0-3.0)$ & 0.314 \\
\hline Suture depth ${ }^{\mathrm{a}}$ & $2.0(1.8-3.0)$ & $2.0(2.0-3.0)$ & 0.619 \\
\hline Suture tension ${ }^{\mathrm{a}}$ & $2.0(1.0-3.0)$ & $2.0(2.0-3.0)$ & 0.081 \\
\hline Suture length ${ }^{\mathrm{a}}$ & $2.0(1.0-3.0)$ & $1.0(1.0-2.0)$ & 0.090 \\
\hline Knots buried ${ }^{\mathrm{b}}$ & $3.0(1.0-3.0)$ & $3.0(1.0-3.0)$ & 0.865 \\
\hline \multicolumn{4}{|l|}{ Post training } \\
\hline Number of sutures & $6(5-7)$ & $6(5-7)$ & 0.564 \\
\hline Time (sec) & $2,255(1,883-2,952)$ & $2,019(1,574-2,862)$ & 0.324 \\
\hline Tissue apposition ${ }^{\mathrm{a}}$ & $3.0(2.0-3.0)$ & $3.0(2.5-3.0)$ & 0.106 \\
\hline Suture depth ${ }^{\mathrm{a}}$ & $3.0(2.0-3.0)$ & $3.0(3.0-4.0)$ & $0.009^{c}$ \\
\hline Suture tension $^{\mathrm{a}}$ & $2.0(2.0-3.0)$ & $3.0(2.0-3.0)$ & $0.003^{c}$ \\
\hline Suture length ${ }^{a}$ & $2.0(2.0-3.0)$ & $3.0(2.0-3.0)$ & $0.043^{c}$ \\
\hline Knots buried $^{\mathrm{b}}$ & $2.0(1.0-3.0)$ & $1.0(1.0-2.0)$ & 0.096 \\
\hline
\end{tabular}

Note: SIM refers to simulator-based training while CADAVER refers to cadaveric-tissue-based training.

ascale: 1 (poor) to 4 (excellent).

${ }^{\text {bScale: }} 1$ (100\% buried) to 3 ( $<50 \%$ buried).

${ }^{c} p<0.05$.

statistically significant improvement in exercise completion after training $(p=0.091[-$ Table 5]).

Additional feedback on the Bioniko simulator was provided by some participants. In response to whether the simulator was comparable to animal tissue for all or some tasks, 9 (25.7\%) said all, 8 (22.8\%) said some, and half, 18(51.4\%), said it was not comparable. In response to whether the simulator was comparable to animal tissue for skill training, a majority, 29 (80.5\%), said all skills could be trained, 4 (11.1\%) said some of the skills, and $3(8.3 \%)$ said none of the skills. As far as the utility of the simulator for training all metrics, 12 (33.3\%) felt all metrics, $8(22.2 \%)$ felt some, and $16(44.4 \%)$ felt none of the training metrics were met. Recommendations for improving
Table 5 Successful completion of exercise at post training (Resident cohort)

\begin{tabular}{|l|l|l|}
\hline & $\begin{array}{l}\text { SIM } \\
(\boldsymbol{n}=\mathbf{3 0})\end{array}$ & $\begin{array}{l}\text { CADAVER } \\
(\boldsymbol{n}=\mathbf{4 9})\end{array}$ \\
\hline $\begin{array}{l}\text { Exercise successfully } \\
\text { completed at post training }\end{array}$ & $15(50 \%)$ & $35(71.4 \%)$ \\
\hline $\begin{array}{l}\text { Not successfully completed } \\
\text { at post training }\end{array}$ & $15(50 \%)$ & $14(28.6 \%)$ \\
\hline $\begin{array}{l}\text { p-Value } \\
\text { (Fisher's Exact test) }\end{array}$ & 0.091 & \\
\hline
\end{tabular}

Note: SIM refers to simulator-based training while CADAVER refers to cadaveric-tissue-based training. 
Table 6 Before-training versus post-training scoring metrics in the SIM and CADAVER groups (Staff cohort)

\begin{tabular}{|l|l|l|l|l|l|l|}
\hline Measures & \multicolumn{2}{|l|}{ SIM } & & \multicolumn{2}{l|}{ CADAVER } & \\
\hline Median (IQR) & Baseline & Post training & $p$-Value & Baseline & Post training & $p$-Value \\
\hline Number of sutures & $5(3-6)$ & $5(3-5)$ & 0.461 & $5(4-6)$ & $3(3-5)$ & $0.026^{\mathrm{c}}$ \\
\hline Time (sec) & $1,104(561-2,090)$ & $927(598-1,166)$ & 0.207 & $2,257(1,579-3,225)$ & $1,101(601-2,330)$ & $0.025^{\mathrm{c}}$ \\
\hline Tissue apposition $^{\mathrm{a}}$ & $3(2.3-3.8)$ & $3.0(2.3-4.0)$ & 0.999 & $3.0(2.0-3.6)$ & $3.0(2.0-3.0)$ & 0.680 \\
\hline Suture depth $^{\mathrm{a}}$ & $3.0(2.3-3.0)$ & $3.0(2.3-3.0)$ & 0.317 & $3.0(2.0-3.0)$ & $3.0(2.3-3.0)$ & 0.180 \\
\hline Suture tension $^{\mathrm{a}}$ & $2.0(2.0-2.8)$ & $2.5(1.3-3.8)$ & 0.317 & $2.3(1.8-3.0)$ & $2.0(2.0-3.0)$ & 0.457 \\
\hline Suture length $^{\mathrm{a}}$ & $3.0(2.0-3.0)$ & $3.0(2.0-3.0)$ & 0.655 & $2.0(1.8-3.0)$ & $2.0(2.0-3.0)$ & 0.518 \\
\hline Knots buried $^{\mathrm{b}}$ & $1.0(1.0-1.0)$ & $1.0(1.0-1.8)$ & 0.414 & $1.0(1.0-2.3)$ & $1.0(1.0-1.8)$ & 0.414 \\
\hline
\end{tabular}

Note: SIM refers to simulator-based training while CADAVER refers to cadaveric-tissue-based training. IQR, interquartile range.

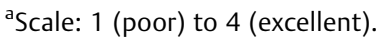

bcale: 1 (100\% buried) to 3 ( $<50 \%$ buried).

${ }^{c} p<0.05$.

Table 7 SIM versus CADAVER groups scoring metrics before training and post training (Staff cohort)

\begin{tabular}{|c|c|c|c|}
\hline & $\operatorname{SIM}(n=8)$ & $\begin{array}{l}\text { CADAVER } \\
(n=8)\end{array}$ & $p$-Value \\
\hline \multicolumn{4}{|l|}{ Before training } \\
\hline $\begin{array}{l}\text { Number of } \\
\text { sutures }\end{array}$ & $5(3-6)$ & $5(4-6)$ & 0.878 \\
\hline Time (sec) & $\begin{array}{l}1,104 \\
(561-2,090)\end{array}$ & $\begin{array}{l}2,257 \\
(748-3,415)\end{array}$ & 0.065 \\
\hline $\begin{array}{l}\text { Tissue } \\
\text { apposition }^{\text {a }}\end{array}$ & $3.0(2.3-3.8)$ & $3.0(1.0-3.5)$ & 0.442 \\
\hline Suture depth & $3.0(2.3-3.0)$ & $2.5(2.0-3.0)$ & 0.574 \\
\hline Suture tension $^{a}$ & $2.0(2.0-2.8)$ & $2.0(1.0-3.0)$ & 0.959 \\
\hline Suture length ${ }^{a}$ & $3.0(2.0-3.0)$ & $2.0(2.0-3.0)$ & 0.328 \\
\hline Knots buried & $1.0(1.0-1.0)$ & $1.0(1.0-1.8)$ & 0.382 \\
\hline \multicolumn{4}{|l|}{ Post training } \\
\hline $\begin{array}{l}\text { Number of } \\
\text { sutures }\end{array}$ & $5(3.0-5.0)$ & $3.0(3.0-5.0)$ & 0.130 \\
\hline Time (sec) & $\begin{array}{l}927 \\
(598-1,166)\end{array}$ & $\begin{array}{l}1,101 \\
(601-2,330)\end{array}$ & 0.442 \\
\hline $\begin{array}{l}\text { Tissue } \\
\text { apposition }^{\text {a }}\end{array}$ & $3.0(2.3-4.0)$ & $3.0(2.3-3.0)$ & 0.505 \\
\hline Suture depth ${ }^{a}$ & $3.0(2.3-3.0)$ & $2.0(2.0-3.0)$ & 0.999 \\
\hline Suture tension $^{a}$ & $2.5(1.3-3.8)$ & $2.0(2.0-3.0)$ & 0.959 \\
\hline Suture length ${ }^{a}$ & $3.0(2.0-3.0)$ & $2.0(2.0-3.0)$ & 0.382 \\
\hline Knots buried & $1.0(1.0-1.0)$ & $1.0(1.0-1.8)$ & 0.999 \\
\hline
\end{tabular}

Note: SIM refers to simulator-based training while CADAVER refers to cadaveric-tissue-based training.

ascale: 1 (poor) to 4 (excellent).

the simulator included more realistic tissue and less cheesewiring during suturing.

Staff pre- and post training data within each group (SIM and CADAVER) are presented in $\boldsymbol{- T a b l e} \mathbf{6}$. There were no significant differences in the SIM group but were in the CADAVER group. There were no significant differences comparing between groups with the exception of time in the pretraining group ( - Table 7). There was no difference in successful completion of
Table 8 Skill retention in Residents and Staff members after training

\begin{tabular}{|l|l|l|}
\hline SIM training & Resident $(\boldsymbol{n}=30)$ & Staff $(\boldsymbol{n}=8)$ \\
\hline Improved & $7(23 \%)$ & $0(0 \%)$ \\
\hline Retained/No change & $17(57 \%)$ & $6(75 \%)$ \\
\hline Worsened & $6(20 \%)$ & $2(25 \%)$ \\
\hline CADAVER training & Resident $(\boldsymbol{n}=49)$ & Staff $(\boldsymbol{n}=8)$ \\
\hline Improved & $14(29 \%)$ & $2(25 \%)$ \\
\hline Retained/No change & $27(55 \%)$ & $4(50 \%)$ \\
\hline Worsened & $8(16 \%)$ & $2(25 \%)$ \\
\hline
\end{tabular}

Note: SIM refers to simulator-based training while CADAVER refers to cadaveric-tissue-based training.

the exercise with $62.5 \%$ of SIM and 75\% of CADAVER successfully completing the exercise $(p=0.999)$.

In regard to skill retention, residents and staff performed similarly with over $75 \%$ retention or improvement regardless of training medium (-Table 8).

\section{Discussion}

The primary goal in the initial repair of an open globe injury is a watertight closure with restoration of structural integrity. Wound closure techniques that must be followed include guidance on suture length, tension, depth, and orientation. ${ }^{10}$ The repair of a simple corneal laceration is a generalizable skill with important implications on vision due to ensuing scarring and astigmatism that can be significantly affected by the above factors in the repair. Surgical simulation becoming mainstream training for resident and attending physicians drives the development, refinement, and validation of simulated tissue models. This study explores the potential of a cornea model for time-limited corneal laceration repair training as a potential alternative to training on cadaveric tissue.

Our results demonstrate that there was no significant difference in CADAVER versus SIM groups in the primary outcome of watertight wound closure of the corneal laceration, which is undoubtedly the most important metric to limit 
the likelihood of infection, preservation of vision, and further surgery in the short term. The CADAVER training group included a higher percentage of residents further along in training/postgraduate year 4 (SIM, 3.3\% versus CADAVER, $16.3 \%)$, though this did not correspond with more experience in the number of prior corneal laceration repairs. Despite this, more residents in the CADAVER group improved compared with the SIM group. Additionally, our results also show that the CADAVER group performed better than SIM group for certain metrics (suture depth, length, and tension) that are associated with poor wound closure and increased amount of induced corneal astigmatism. This may lead to immediate further surgery in the case of incomplete wound closure or to poor best corrected visual acuity and the need for rigid or specialty contact lenses or even corneal transplantation to alleviate excessive irregular astigmatism.

SIM training may be useful in training ophthalmologists, though further study is certainly warranted to better evaluate the effectiveness of this training method. Also, while the CADAVER group seemed to show more improvement from pre- to post-training metrics, the SIM group also trended toward improvement, though this did not reach statistical significance. A smaller sample size of the SIM group (SIM, $n=30$; CADAVER, $n=49$ ) may have contributed to this lack of statistical significance.

This study, on a more limited basis, evaluated the use of a simulator for an already board-certified ophthalmologist. Of the eight in each group, six demonstrated retention or sustained suturing skills. This suggests that, as they would be more likely to be familiar with suturing human corneas, the use of SIM training may be sufficient to "refresh" skills and result in the similar outcomes when compared with CADAVER training. Interestingly, some residents and staff in SIM and CADAVER groups demonstrated worsening, as shown in - Table 8. This suggests that either the practice time was insufficient or fatigue started playing a role. It may be better to increase the number of practice sessions and allow recovery time between practice and post-training evaluation. Given the small sample size, we would encourage further research into the possibility of using a simulator for refresher training.

There were numerous limitations to this study, which primarily served to provide proof-of-concept for this simulator training. The largest drawback was the limited sample size. Enrollment was open to military and civilian residents attending the Tri-Service Ocular Trauma Skills Laboratory, a condition made necessary by space and funding limitations along with the difficulty of including large numbers of ophthalmology residents. The study was also limited greatly by the duration of training; 90 to 120 minutes of practice time is likely insufficient for the training of ophthalmologists in the complicated and precise elements evaluated in this study. This time period had been chosen based on the maximum time recommended by Ericsson for any individual training session. ${ }^{11}$ One of the goals of validating a simulator would be the ability to increase overall trauma training time by deploying the simulators to different centers throughout the DoD, thus overcoming a current significant limitation in our readiness. SIM training was also likely limited by its novelty. Most residents have had experience coming into the Tri-Service Ocular Trauma Skills Laboratory engaging in CADAVER training for corneal lacerations. However, none had prior experience working with Bioniko eye ophthalmic surgery models. While they are designed to simulate ocular tissue as accurately as possible, they remain unique from true live tissue; therefore, training and performance may have been limited by the learning curve involved in working with a new training platform. Additionally, pre- and post-training testing was performed on cadaveric tissue, so the CADAVER group had an inherent advantage of being more familiar with the platform having just spent 90 to 120 minutes with it. The majority of participants, 29 (80.5\%), said all skills could be trained, $4(11.1 \%)$ said some of the skills, and $3(8.3 \%)$ said none of the skills. However, about half (51.4\%) said the Bioniko eye was not comparable to cadaver eyes. Of note, feedback was not solicited on whether pig eyes were comparable to human eyes, limiting utility of the question.

There are many benefits of SIM over CADAVER training models, such as the increased availability over cadaver/ exenterated eyes, decreased contamination of spaces (if spaces are used for human patients as well), and no cross-contamination of instruments. It is impossible to have pig eyes immediately available to an ophthalmologist for refresher training shortly before treating a trauma patient. With a simulator model, it becomes possible for an ophthalmologist to refresh skills immediately upon becoming aware of a pending medical evacuation from a conflict zone.

Overall, this study demonstrated that for resident ophthalmologists, SIM training is sufficient for achieving the primary outcome of watertight wound closure. However, CADAVER training is superior for wound metrics for the ideal closure (e.g., induced astigmatism). For attending ophthalmologists, simulator training may be useful for retention of skills though very limited by small sample size. Of note, the Bioniko model is one of many potential options to explore in this domain. We hope the effort to continue assessing available simulation models will drive the development of models to be more realistic and possibly more advanced in feedback, guiding, and preparing future ophthalmologists.

\section{Meeting Presentation}

Portions of this material were presented at the annual meetings of the Military Health System Research Symposium, Orlando, Florida, August 2016 and 2017.

\section{Disclaimer}

The views expressed in this article are those of the author (s) and do not reflect the official policy of the Department of the Army/Navy/Air Force, Uniformed Services University, Defense Health Agency, Department of Defense, or the U.S. Government. Discussion or mention of any commercial products or vendor names within this publication does not constitute endorsement or implied endorsement on the part of the Department of Defense or any other organization as stated above. 
Financial Support

Funded by the U.S. Army Medical Research and Materiel Command Award \#TL100010.

\section{Conflict of Interest}

No conflicting relationship exists for any author on this article.

\section{References}

1 Department of Defense. Joint theater trauma registry. https://jts. amedd.army.mil/ Accessed February 03, 2021

2 Vlasov A, Ryan DS, Ludlow S, Weichel ED, Colyer MH. Causes of combat ocular trauma-related blindness from Operation Iraqi Freedom and Enduring Freedom. J Trauma Acute Care Surg 2015;79(04, Suppl 2):S210-S215

3 Weichel ED, Colyer MH. Combat ocular trauma and systemic injury. Curr Opin Ophthalmol 2008;19(06):519-525

4 McCannel CA, Reed DC, Goldman DR. Ophthalmic surgery simulator training improves resident performance of capsulorhexis in the operating room. Ophthalmology 2013;120(12):2456-2461

5 Pokroy R, Du E, Alzaga A, et al. Impact of simulator training on resident cataract surgery. Graefe's Arch Clin Exp Ophthalmol 2013;251(03):777-781
6 Department of Defense(DoD)Instruction. 3216.01.https://www.esd. whs.mil/Portals/54/Documents/DD/issuances/dodi/321601p.pdf Accessed February 03, 2021

7 Physicians Committee for Responsible Medicine. Animal use in advanced trauma life support (ATLS) courses in the United States and Canada. An ongoing survey https://www.pcrm.org/ethicalscience/ethical-education-and-training/survey-of-trauma-training-programs. Accessed April 2, 2020

8 Cabot F, Chhadva P, Joag M, et al. Assessment of corneal suturing performance using the Bioniko ophthalmic surgery models in inexperienced vs experienced ophthalmic surgeons. Invest Ophthalmol Vis Sci 2015;56(07):1555-1555

9 Sykes S, Chou E, Mazzoli RA, et al. Comparison of simulationbased versus live tissue-based ocular trauma training on novice ophthalmologists: repair of marginal eyelid laceration model. J Acad Ophthalmol 2018;10(01):61-68

10 Cho RI, Savitsky E. Ocular trauma. In: Lenhart MK, Savitsky E, Eastridge B, eds. Combat Casualty Care: Lessons Learned from OEF and OIF. Falls Church, VA: Office of the Surgeon General, Department of the Army; 2012

11 Ericsson KA. Deliberate practice and the acquisition and maintenance of expert performance in medicine and related domains. Acad Med 2004;79(10, Suppl):S70-S81 